\title{
La investigación en instituciones de educación superior
}

\author{
Investigation in institutions of higher education
}

Conferencia Magistral del III Congreso de Investigación Científica, realizado en la ciudad de Trujillo, Perú; organizado por la Universidad César Vallejo

Este documento fue elaborado durante el presente año, y es producto de la recopilación de criterios, opiniones y puntos de vista de todos los directores de las principales noventa universidades privadas de México y resalta la importancia de la investigación, la labor de la universidad en la investigación y la investigación como una función básica de la universidad.

¿Por qué debemos impulsar la investigación en las universidades privadas y no solo en las púbicas?

En México, en todo el siglo XX y en lo que va del presente siglo, la investigación ha sido prácticamente exclusiva de las universidades públicas. Tenemos dos grandes universidades estatales, la Universidad Nacional Autónoma de México y el Instituto Politécnico Nacional, que entre ambas rebasan los 150 mil estudiantes de su matrícula permanente. Se trata de dos grandes instituciones y son las que prácticamente desarrollan la poca investigación generada en el país. Las universidades privadas, en cambio, no están haciendo investigación.

En América Latina no hay país que esté realmente impulsando la investigación. Hacemos investigación pero poca, hay escasos investigadores y los estudiantes no se interesan en la investigación. ¿De quién es la culpa?, ¿̇de los estudiantes o de las instituciones que no hemos sabido motivarlos e interesarlos en la investigación?

¿Por qué debemos entonces impulsar la investigación?, primero, por lo obvio, lo que todo el mundo considera la palabra mágica: "las acreditaciones". Hoy muchas universidades privadas

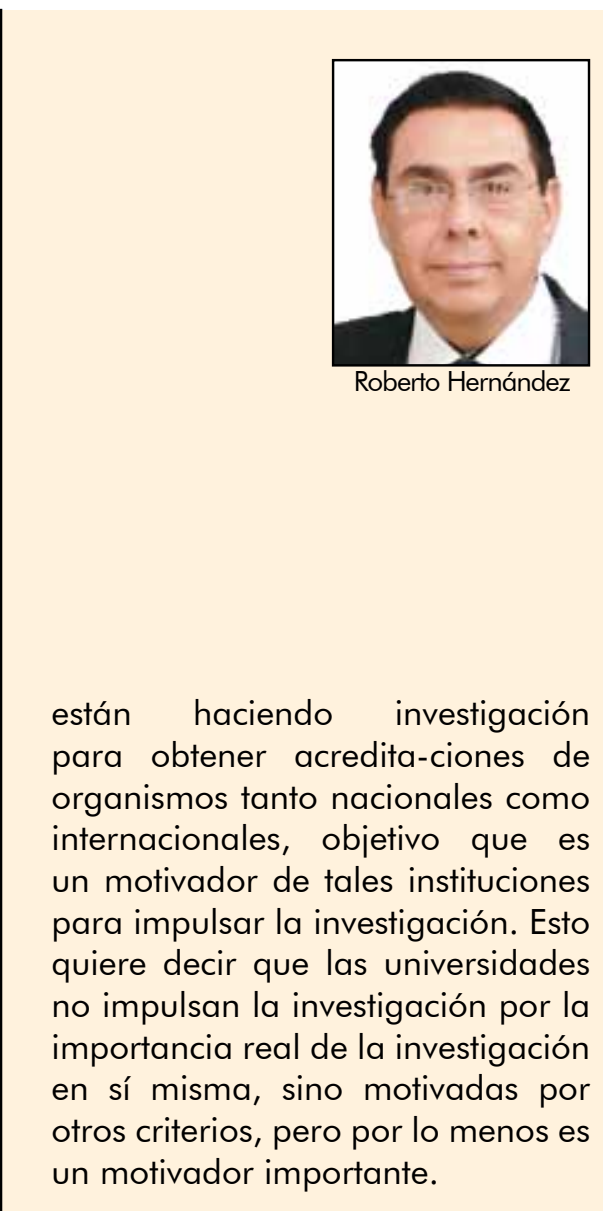

Otro motivador es el posicionamiento entre las universidades por captar alumnos. La captación de estudiantes es vital para cada institución de educación superior privada, porque el principal ingreso son los fondos provenientes de ellos.

1 Director del Centro de Investigación de la Universidad de Celaya, México; director del Doctorado en Administración de la Universidad de Celaya; profesor e investigador del Instituto Politécnico Nacional; director del Centro de Investigación en Métodos Mixtos de la Asociación Iberoamericana de la Comunicación; autor del best seller "Metodología de la Investigación" 
También para ganarle a la competencia, llegar a nuevos nichos de mercado, publicitarse o promoverse.

Un tercer motivador es el intercambio con las universidades del extranjero. Las universidades privadas hoy quieren estar muy vinculadas con otras instituciones; en el caso de América Latina, con otras instituciones latinoamericanas y europeas. En México se ha dado un impulso muy importante a lo que llamamos la doble titulación; es decir, la gente obtiene su título de nuestras universidades y va al extranjero un semestre o un año, para así obtener el título de la otra universidad. En el caso de nuestra universidad, tenemos convenios con la Universidad Autónoma de Barcelona, la Universidad Estatal de New York y Washington en Estados Unidos. Tenemos diferentes convenios que han hecho que nuestra universidad se impulse en la investigación, porque precisamente esas universidades hacen investigación. Por ejemplo, recientemente llegaron de varias universidades para hacer un intercambio con nosotros, y lo primero que nos preguntaron fue: "¿QQué proyecto de investigación vamos hacer en conjunto?". Si no hiciéramos investigación, pues no podríamos aliarnos.

Asimismo, pretendemos impulsar la investigación porque deseamos un perfil más competitivo de nuestros alumnos, que sepan resolver problemas, tomar decisiones, gestionar o administrar con conocimiento. En este país estamos impulsando que parte importante de las competencias, habilidades y conocimientos del estudiante promedio sean en investigación, pero primero tenemos que hacer conscientes a los jóvenes de para qué le va a servir la investigación en sus trabajos cotidianos, si el joven no logra conectar su vida cotidiana y su desarrollo profesional con la investigación, no se va a interesar en ella.

Del mismo modo para obtener una mayor vinculación con el entorno social y además como parte de nuestra responsabilidad social. Las universidades tienen la obligación de ayudar a resolver los problemas de nuestras comunidades y ciudades. Nuestra universidad, por ejemplo, hace mucha investigación para ver qué problemas existen respecto al agua, los residuos sólidos, la inseguridad en México, para ver cómo desarrollar las pequeñas empresas, cómo potenciar las microempresas. Hacemos mucha investigación, y creemos que es parte de nuestra responsabilidad social.

Profesionalizar a nuestros docentes. Yo no concibo un docente que no haga investigación. Un docente que no investiga va a quedar completamente obsoleto; el conocimiento es exponencial, los profesores tienen que estar haciendo investigación. Hemos encontrado en todo América Latina profesores que enseñan el curso de Investigación y no hacen investigación, y cuando se les pregunta: "¿Qué has publicado en este último año?", ellos responden, nada; "¿̇y el año pasado?", tampoco. Hay profesores que se pasan veinte años enseñando Métodos de Investigación y no investigan ni publican. La tarea investigativa debe ser algo que todo profesor de cualquier disciplina, sobre todo los profesores de tiempo completo, es decir que su principal fuente de trabajo es la universidad, tendría que estar haciendo. De hecho, ya establecimos en nuestra universidad el criterio de que todos los profesores tienen que publicar un trabajo como mínimo al año y en revistas arbitradas.

Por otra parte, se está creando el puesto de investigador, porque muchas veces decimos que tenemos tantos profesores investigadores, pero a la hora de ver cuánto están publicando, las cifras no son importantes. Toda universidad debería estar publicando decenas de artículos y produciendo conocimiento, pero esto no se está haciendo.

La investigación sirve a las universidades privadas para obtener fondos, para que los centros de investigación puedan ser autofinanciables en estas instituciones; lo hemos demostrado con varios casos de centros de investigación que vendiendo servicios de investigación desarrollan 
esta tarea. Hacen investigación para generar conocimiento, tecnología, pero también venden servicios de investigación a gobiernos provinciales, a empresas de la región, entre otros, con cuyos servicios obtienen recursos importantes.

Es complejo lograr que las instituciones privadas de educación superior fomenten la investigación, sin embargo, se puede iniciar dando algunos pasos, el primero, es que tenemos que generar una cultura de investigación, un cambio cultural; la cultura de investigación no está presente en la mayoría de las universidades y de los universitarios. Si nosotros les preguntamos a los jóvenes: "¿̇Les interesa la investigación?", la verdad, nos van a decir que no. Cuando van a leer las materias que les van a tocar y aparece por ahí un curso de Investigación, empiezan a lamentarse como si fuera una tortura. Entonces, tenemos que generar un valor de la investigación, que la investigación sea un detonante, empezando por los alumnos y profesores, que sea un valor que se recompense, que se promocione a través de todos los medios de comunicación de la universidad sobre la base de un plan detallado.

Por otro lado, simultáneamente en el proceso de aculturación, recomendamos hacer una evaluación de cómo está la investigación en la universidad, qué conocimientos tienen los jóvenes, qué actitudes muestran cuando les hablamos de la investigación, qué piensan y cómo definen la investigación; medir el nivel del interés que tienen y evaluar qué se está haciendo en esta materia con todos los profesores y en todos los niveles.

En toda universidad tiene que haber un centro de investigación, un club de investigación, un lugar donde los alumnos participen orientados por sus maestros. En la universidad de mi procedencia llevamos cerca de diez años desde que se creó el club de investigación donde acuden alumnos que les interesa la investigación y hacen una investigación completa, algunos profesores los apoyamos en el desarrollo de sus investigaciones y al final los publican. Uno puede pensar que los jóvenes no se interesan en la investigación, eso no es cierto. Cuando al joven se le explica, ve la utilidad, trabaja en un problema de investigación que le interesa, se motiva, y se ve que son muy dinámicos, se juntan entre ellos, se reúnen un fin de semana, trabajan con entusiasmo, producen, levantan sus datos, los analizan y los publican; pero necesitamos darles canales de expresión de sus trabajos de investigación y, por supuesto, normalizar la función de investigación y documentarla.

Entonces, hay que saber cómo estamos y a partir del diagnóstico empezar a desarrollar algunas acciones. Lo primero será capacitar a los docentes en investigación, actualizarlos para que trabajen en cuestiones de investigación; muchas veces ocurre en las universidades que un profesor ha publicado y el resto de la universidad no sabe de tal publicación, caso que es inconcebible en universidades de Estados Unidos, Canadá, Inglaterra. En América Latina ocurre que no sabemos lo que están publicando nuestros colegas de la misma universidad. Por ejemplo, en la universidad de Sinaloa, alguien de Arquitectura ya iba publicando, pero nadie en la universidad lo sabía más que los alumnos de ese profesor. Por esta razón, tenemos que hacer un inventario de todos los esfuerzos, de todos los productos de investigación, de todas las tecnologías que se están desarrollando y también tener un centro de investigación con una estructura simple y flexible.

A nosotros nos ha funcionado trabajar con investigadores jóvenes, formarlos desde los primeros semestres en el club de investigación y que vayan haciendo sus investigaciones; luego al egresar y empezar sus posgrados, son gente entre 23, 26 o 27 años, que conocen de investigación, de herramientas y han trabajado varios planteamientos, y pueden ser excelentes docentes de investigación porque conectan con los jóvenes de su edad. Los maestros jóvenes de investigación son maravillosos porque entienden, trabajan el mismo lenguaje, no hay una gran distancia ni psicológica ni en el lenguaje con los alumnos. 
Teniendo una mentalidad de apertura, el centro de investigación no puede convertirse en una entidad política, en un juego administrativo porque entonces se acaba esta idea. Al principio se centraliza un sector para toda la universidad, pero conforme crezca la universidad o evolucione el programa para instaurar la cultura de la investigación, se va descentralizando en diferentes unidades académicas: por facultad, por escuela o por conjunto de escuelas y así crear centros de investigación periféricos.

Respecto a los integrantes del centro de investigación, ¿̇qué características deben tener?, ¿̇cuál es el perfil sugerido?. Primero, que tengan una actitud proactiva, que le encante hacer investigación; segundo, un horario flexible, el investigador no está sujeto a horarios y cuando está concentrado en un problema de investigación o una duda, puede pasar un día, una noche completa trabajando, hasta cierto punto con la obsesión de encontrar lo que busca. La investigación siempre ha sido de trabajo en equipo, de colaboración; que sepan generar documentos, capacitarlos de manera permanente, debido a que en la investigación nunca se termina de aprender, yo no conozco alguien que sepa mucho de investigación, siempre hay más que aprender.

¿Qué conocimientos deben tener?, esto es muy obvio, deben de saber de investigación cuantitativa, cualitativa y mixta; también deben conocer cómo participar en convocatorias nacionales e internacionales, cómo obtener recursos de investigación. Hace una semana platicaba con el Presidente de la Unión Europea y me decía: "Existen dos líneas de investigación donde hay muchos recursos de muchos países europeos para financiar proyectos de investigación, se trata de medio ambiente e integración de la Unión Europea con América Latina; pero no nos presentan proyectos de investigación". Del mismo modo, deben de tener conocimientos en redacción de todo tipo de documentos y en mercadotecnia de servicios, así podríamos ir a la alcaldía y ofertar nuestra ayuda, por ejemplo, para desarrollar tecnología apropiada para el problema de recolección de la basura, que es un problema que al menos en México es muy grande; apoyo para el tratamiento de aguas; análisis del problema de inseguridad; resolución de problemas tecnológicos, etc.

Los jóvenes del centro de investigación deben saber mercadear servicios de investigación, además de hacerlos o desarrollarlos. Nosotros hemos tenido alumnos que han ganado premios nacionales en investigación, y a partir de ahí establecimos contactos con los medios de comunicación para que promuevan las investigaciones que están haciendo, hecho que nos permite fortalecer una cultura de investigación.

También desarrollamos eventos con el club de investigación, comolas ferias tecnológicas donde los estudiantes presentan sus investigaciones y van científicos a evaluarlas con la posibilidad de que los alumnos ganen becas para que trabajen con un científico en las investigaciones y proyectos diversos.

Una revista de investigación editada y publicada por jóvenes ejercerá presión en sus profesores, porque si el alumno publicara, el maestro de investigación también empezará a publicar.

En nuestra universidad estamos aceptando la publicación de artículos como tesis, es decir en lugar de entregar la tesis, se realiza la publicación de un artículo científico, un trabajo de altísima calidad evaluada por pares y publicada por un journal científico, lo que conduce a la titulación. Así se demuestra que se sabe de investigación. Este caso, sin embargo, ha sido polémico para muchas personas, pues se deja la tesis como un documento empastado que queda en una biblioteca y que muchas veces nadie los consulta, por lo que nosotros aceptamos esta otra opción.

La creación de la certificación en investigación para nuestros profesores que otorgue el centro de investigación, es importante porque éstos reconocen sus 
limitaciones y el centro de investigación cubre esa necesidad, se dan cursos y talleres al respecto y generamos conocimiento a los profesores sin obligarlos, mejorando así esta cultura de investigación, más la presión de los alumnos, los profesores empiezan a dar cuenta de que ya están obsoletos y buscan ampliar sus conocimientos y tener todos los documentos, primero el documento rector de investigación, el equivalente a lo que los americanos llaman el white paper (políticas de investigación), la visión, las premisas, las estrategias, las líneas de investigación, etc.

Son muy importantes los parámetros de calidad de la investigación cuantitativa y cualitativa, tener las publicaciones oficiales y por lo menos uno o dos journal de jóvenes para jóvenes. Asimismo, tener una serie de manuales, como mínimo estamos sugiriendo un manual para la elaboración de tesis, tesinas y reportes; otro para proyectos y propuestas; manual para la elaboración de artículos y rúbricas para evaluar la calidad de las investigaciones; guías para la presentación de investigaciones, entre otros, y que toda la universidad conozca.

Después del diagnostico, estructurar el centro de investigación y crear la serie de documentos que soporte la labor, se debe pasar a revisar el currículo en investigación y que debe tener tres ejes centrales, que son la investigación cuantitativa, cualitativa y mixta. Sabemos que el método cuantitativo es más común en las ciencias puras; en algunas ciencias, como la Antropología, también es común el enfoque cualitativo; el enfoque mixto ha sido muy polémico en América Latina.

Hoy puedo decirles que después de 16 años de estar proponiendo junto a autores norteamericanos los métodos mixtos, hay una gran cantidad de textos de investigación mixta y hay gente que está haciendo tal investigación.

Muchosempezamosautilizar la investigación mixta, ya no con los métodos cuantitativos o cualitativos separados; ahora decimos que iniciamos nuestra investigación a partir del planteamiento del problema y que luego es lo demás, es el planteamiento y son las circunstancias lo que nos inclina hacia determinados métodos. La investigación es como un conjunto de herramientas, y se selecciona la herramienta apropiada de acuerdo con la tarea; si lo que tenemos es un problema de investigación que requiere que clavemos algo, utilizaremos un martillo, no una sierra; si el problema es cortar, no usamos un martillo; así vemos la metodología, ¿̇qué herramientas necesito?, ¿̇experimento, observación? El método está sujeto al planteamiento del problema; entonces, en este sentido se puede enseñar el proceso de la investigación y en el camino ir enseñando investigación cuantitativa y cualitativa y los métodos mixtos.

Los famosos concursos de investigación son muy importantes, el dar premio a los alumnos, ayudarles a publicar sus trabajos. Por ejemplo, lo que nosotros hacemos es que si un trabajo no puede ser aceptado en la revista institucional pero tiene cuestiones de interés, pues se publica en un periódico o un programa de radio.

Una vez que estén sólidos los comités de investigación, se inicia con una campaña para que desde el alcalde, gobernador, diputados y senadores sepan que en esta universidad se hace investigación de calidad; se inicia con la búsqueda de otras alternativas como hacer convenios con otras universidades, que están funcionando de maravilla.

Aprovechar las redes sociales para la investigación es muy interesante y se pueden debatir temas de cómo es la situación en su país con respecto a distintos temas de interés de los jóvenes. El Facebook y otras tecnologías que existen ahora han hecho que los jóvenes vuelvan a leer.

Entrar en contacto con todas las asociaciones, los congresos, insertar artículos, hay muchas oportunidades para obtener recursos a pesar de la crisis europea, y están ahí, esperando que lleguemos. México tiene fondos en el Consejo Nacional de Ciencia y Tecnología para proyectos latinoamericanos donde se 
vinculen al menos dos países, que es el requisito.

Consolidar, internacionalizar y renovar, pero tenemos que estar en contacto con las universidades privadas y trabajar juntos, ir viendo hacia donde orientamos la investigación. Tenemos que empezar a fomentar la investigación entre los jóvenes, motivándolos y mostrándoles el porqué es importante hacer y publicar los resultados de sus investigaciones.

Muchas gracias. 